\title{
GRAFIR BATU ALAM DENGAN MESIN CNC ROUTER UNTUK MENINGKATKAN RAGAM PRODUK KREATIF INDONESIA
}

\author{
Suharto $^{1)}$, Kunto Purbono ${ }^{2)}$, Ahmad Supriyadi ${ }^{3)}$, Karnowahadi ${ }^{4)}$ \\ ${ }^{1,2,3)}$ Jurusan Teknik Mesin, Politeknik Negeri Semarang \\ ${ }^{4)}$ Jurusan Administasi Bisnis, Politeknik Negeri Semarang \\ ${ }^{1)}$ pakharto58@mail.com, ${ }^{2)}$ kunto.purbono@ gmail.com, ${ }^{3)}$ ahmadsupriyadi32@ gmail.com, \\ 4)karnojogja@gmail.com
}

\begin{abstract}
The development of Computer Numerical Controller (CNC) machines for creative product manufacturing needs to be encouraged to improve the variety and quality of results in Indonesia. Manually engraving natural stone (marble, granite) by relying on the skills of people and simple equipment will produce a product with a long time. Competition in business and industry is needed to improve effectiveness and efficiency with short time-making indicators, low prices, and variety of products that interest consumers. The aim of the researh was to find the most effective and efficient machining parameters, to analyze the factors affecting surface roughness, and to enrich the variety of creative product designs of marble materials. This research uses experimental method approach that to find the effect of cutting speed variable, the feedrate, the depth of cutting to the quality of surface roughness. The results of the reseacrh found machining parameters of cutting speed $30(\mathrm{~m} / \mathrm{min})$, spindle rotation $12000(\mathrm{rpm})$, feedrate $2000(\mathrm{~mm} / \mathrm{min})$. Factor analysis that influence to marbled surface roughness of marble higher feedrate, depth of cutting hence higher also roughness value surface of marble stone. Apllication computer and engineering software able to increase creative product design variety.
\end{abstract}

\begin{abstract}
ABSTRAK
Pengembangan mesin Computer Numerical Controller (CNC) router khusus pembuatan kerajinan produk kreatif perlu didorong untuk meningkatkan ragam dan kualitas hasil di Indonesia. Grafir batu alam (marmer, granit) secara manual dengan mengandalkan ketrampilan orang dan peralatan sederhana akan menghasilkan produk dengan waktu lama. Kompetisi dalam dunia usaha dan industri diperlukan untuk meningkatkan efektifitas dan efisiensi dengan indikator waktu pembuatan singkat, harga murah, variasi disain lebih banyak dan menarik. Tujuan penelitian untuk menemukan parameter pemesinan yang efektif dan efisien, menganalisis faktor yang berpengaruh terhadap kekasaran permukaan, dan pengkayaan ragam disain produk kreatif bahan batu marmer. Penelitian ini menggunakan pendekatan metode eksperimen yaitu penelitian untuk menemukan pengaruh variabel putaran spindle, kecepatan pemakanan, kedalaman pemakanan terhadap kualitas kekasaran permukaan. Hasil penelitian menemukan parameter pemesinan kecepatan potong 30 (m/min), putaran spindle 12000 (rpm), kecepatan/laju pemakanan $2000(\mathrm{~mm} / \mathrm{min})$. Analisis faktor yang berpengaruh terhadap kekasaran permukaan grafir marmer semakin tinggi kecepatan/laju pemakanan, kedalaman pemakanan maka semakin tinggi pula nilai kekasaran permukaan batu marmer. Aplikasi komputer dan engineering software mampu meningkatkan ragam disain produk kreatif.
\end{abstract}

\section{Kata kunci: Batu alam; mesin CNC router; produk kreatif; daya saing}

\section{PENDAHULUAN}

Seiring berkembangnya usaha mikro, kecil, menengah (UMKM) khususnya pengrajin grafir batu alam (marmer, granit) yang berada di daerah Pekalongan, dalam produksinya masih menemui beberapa kendala. Pengrajin grafir marmer, granit yang sering dilakukan adalah grafir prasasti, batu nisan, vandel, dan nomor rumah. Kendala utama yang dialami oleh pengrajin grafir marmer adalah keterbatasan sumber daya manusia (tukang), variasi disain produk, kecepatan waktu, dan kualitas hasil proses kerajinan secara manual membutuhkan waktu yang lama variasi disainnya juga terbatas. Hal ini yang mendorong untuk dilakukan upaya mengoptimalkan proses produksi kerajinan grafir dengan menggunakan mesin cnc router untuk meningkatkan produksi dan ragam produk kreatif bahan batu alam. Mesin cnc router merupakan jawaban dari tuntutan UMKM/industri akan produk yang berkualitas meliputi keakurasian yang tinggi, kepresisian tinggi, bentuk benda yang komplek dan kemampuan menghasilkan produk secara massal. Mesin CNC (computer numerical controller) router 


\section{JURNAL SIMETRIK VOL 8, NO. 2, DESEMBER 2018}

merupakan mesin perkakas yang digunakan untuk melakukan pemotongan (cutting), pengukiran (engraving), dan pemberian tanda (marking) benda kerja dengan pahat yang berputar pada sumbunya, permukaan yang dipotong baik berbentuk datar, sudut atau melengkung. (Salam,A.Rohman, 2013: Nanda Afriliyan, 2013)

Teknologi proses pemesinan $\mathrm{CNC}$ router mengalami perubahan sejalan dengan era globalisasi dari produk-produk budaya dan teknologi konvensional menuju teknologi modern (Suryanto,dkk:2014; Suharto,dkk: 2016). Dunia menjadi tempat yang sangat dinamis dan kompleks sehingga kreativitas dan pengetahuan menjadi suatu aset yang tak ternilai dalam kompetisi dan pengembangan ekonomi kreatif. Ekonomi kreatif adalah sebuah konsep di era ekonomi baru yang penopang utamanya adalah informasi dan kreativitas di mana ide dan stock of knowledge dari Sumber Daya Manusia (SDM) merupakan faktor produksi yang utama dalam kegiatan ekonomi. Ekonomi kreatif dikenal sebagai konsep pengembangan ekonomi yang mengandalkan daya kreasi untuk menciptakan produk maupun menambah nilai/value, sehingga ekonomi kreatif memiliki potensi besar untuk menjadi salah satu sektor penggerak roda perekonomian daerah. Ekonomi kreatif juga dipahami tidak hanya mengenai penciptaan nilai tambah secara ekonomi, tetapi juga penciptaan nilai tambah secara sosial dan mental. (Komsan Suriya, 2012; Ardista, 2014)

Dalam proses pemesinan secara manual maupun CNC (Computer Numerical Control), output yang diharapkan adalah mampu melakukan proses pemesinan secara cepat dan skala yang besar dan

spesifikasi geometri yang diharapkan. Namun pada hasil proses pemesinan sering terjadi kekasaran pada permukaan benda yang dikerjakan sangatlah berbeda. Kekasaran permukaan adalah salah satu penyimpangan yang disebabkan oleh kondisi pemotongan dari proses pemesinan. Oleh karena itu, untuk memperoleh produk bermutu berupa tingkat kepresisian yang tinggi serta kekasaran permukaan yang baik, perlu didukung oleh proses pemesinan yang tepat. Karakteristik kekasaran permukaan dipengaruhi oleh beberapa parameter pemotongan diantaranya yaitu kecepatan spindel (spindle speed), kedalaman pemakanan (depth of cut), alur pahat (Toolpath), dan material benda kerjanya.

Ardiansyah (2011) dalam penelitiannya menghasilkan pengaruh parameter pemesinan terhadap kekasaran permukaan kayu jati. Patel K.P. (2012) menganalisis eksperimen kekasaran permukaan pada proses pemesinan CNC milling 3-axis dengan bahan aluminium. Penelitian saat ini menemukan parameter pemesinan CNC router terhadap kekasaran permukaan batu marmer dan menganalisis faktor yang paling berpengaruh terhadap kekasaran permukaan.

\section{TINJAUAN PUSTAKA}

Kecepatan potong (cutting speed) merupakan kecepatan gerak putar cutting tools yang dinyatakan dalam meter per menit. Kecepatan potong ini tergantung dari bahan benda kerja yang akan dipotong dan bahan dari cutting tools itu sendiri. Untuk mencari kecepatan potong rumusnya dengan:

$$
V=\frac{\pi \cdot d \cdot n}{1000}
$$

\section{Keterangan:}

$\mathrm{V}=$ kecepatan potong $(\mathrm{m} / \mathrm{min})$

$\mathrm{d}=$ diameter cutting tool $(\mathrm{mm})$, dan

$\mathrm{n}=$ putaran spindle $(\mathrm{rpm})$

Putaran spindle merupakan kemampuan putaran mesin dalam satu menit. Nilai kecepatan potong jenis bahan batu marmer setara dengan baja $\mathrm{V}=30(\mathrm{~m} / \mathrm{min})$ maka putaran spindle dapat dihitung dengan persamaan (1). Kecepatan/laju pemakanan (feedrate) merupakan gerak makan (f) jarak lurus yang ditempuh cutting tool dengan laju konstan relatif terhadap benda kerja dalam satuan waktu $(\mathrm{mm} / \mathrm{min})$.

$$
V_{f}=n f_{z} z
$$

Keterangan:

$\mathrm{Vf}=$ kecepatan/laju pemakanan $(\mathrm{mm} / \mathrm{min})$,

$\mathrm{n}=$ putaran spindle (rpm),

$\mathrm{z}=$ jumlah gigi pada cutting tool, dan

$\mathrm{f}_{\mathrm{z}}=$ kecepatan/laju pemakanan pergigi ( $\mathrm{mm} /$ tooth)

Kedalaman pemotongan (depth of cut) ditentukan berdasarkan selisih tebal benda kerja awal terhadap tebal benda kerja akhir. Besarnya kedalaman potong berhubungan erat dengan kecepatan pemakanan dan juga dari diameter cutting tool tersebut.

Rumusan parameter pemesinan $\mathrm{CNC}$ router terdiri putaran spindle (rpm), kecepatan/ laju pemakanan $(\mathrm{mm} / \mathrm{min})$, dan kedalaman pemotongan $(\mathrm{mm})$ yang berpengaruh terhadap kekasaran permukaan batu marmer/granit. Selanjutnya menganalisis faktor yang berpengaruh terhadap kekasaran permukaan. Lalu proses pengkayaan ragam produk kreatif melalui input foto pada halaman software CorelDRAW menjadi siluet, selanjutnya dengan software Aspire Vectric dihasilkan notepad g-code lalu eksekusi mach-3 pada mesin $\mathrm{CNC}$ router.

Tujuan penelitian untuk mendapatkan setting optimal parameter pemesinan CNC router, menganalisis faktor yang berpengaruh terhadap kekasaran permukaan batu marmer. Kondisi optimal parameter pemesinan yang tepat dan efisien waktu, kekasaran permukaan, keamanan bagi cutting tools guna pengkayaan ragam produk kreatif Indonesia.

\section{METODOLOGI}

Lokasi, Waktu, Bahan, dan Peralatan. Tempat pelaksanaan kegiatan penelitian di Laboratorium perancangan Politeknik Negeri Semarang dan Erriesa Griya Cetak Pekalongan. Waktu pelaksanaan kegiatan berlangsung mulai bulan April sd Agustus 2018. Bahan yang digunakan antara lain batu alam jenis marmer ukuran panjang 300 (mm); lebar 250 (mm); tebal $10(\mathrm{~mm})$. Mesin dan Peralatan yang digunakan mesin CNC router dengan sistem pendingin (collant), 


\section{JURNAL SIMETRIK VOL 8, NO. 2, DESEMBER 2018}

sistem penjepit, cutting tools bahan karbida jenis Engraving bits sudut $60^{\circ}$ Tip diameter $6 \mathrm{~mm}$, dan surface roughness tester.

Pelaksanaan grafir batu alam dengan mesin CNC router untuk meningkatkan ragam produk kreatif Indonesia terdiri dari tahapan, gambar 1 :

1. Identifikasi kebutuhan kerajinan Grafir batu alam (marmer/granit), jenis bahan, jenis produk kerajinan.

2. Disain motif grafir batu marmer/granit dilakukan dengan menggunakan komputer dengan beberapa software coreldraw, aspire vectric, dan mach-3.

3. Bahan batu marmer disiapkan di meja kerja mesin CNC router dijepit bagian tepi sehingga tidak bergerak arah sumbu X, sumbu Y, dan sumbu Z. Sistem pendingin air yang terpasang pada mesin $\mathrm{CNC}$ router dipastikan dapat bekerja optimal mendinginkan cutting tools selama proses pemesinan berlangsung.

4. Mesin CNC router 3-Axis yang digunakan produksi lokal dengan spesifikasi: machine dimension: 1540x1005x1500 (mm); working area: 600x400x150 (mm); spindle motor: $3(\mathrm{Kw}) 18000$ (rpm); axis drive : stepper motor $\mathrm{X}=8.7(\mathrm{Nm})$, $\mathrm{Y}=8.7(\mathrm{Nm}), \mathrm{Z}=7.7(\mathrm{Nm})$, tool holder: collet ER20, max tool dia. 13 (mm); Power: AC220V/50Hx,3.5 (Kw); Komputer: Dualcore 2GB RAM, 15" Touchscreen LCD Monitor; software: mach-3 CNC control (www.machsupport.com) . Mesin CNC router disetting dengn parameter putaran spindle, dept of cut, feedrate, jenis cutting tools, dan bahan batu alam marmer/granit.

5. Ujicoba pemesinan dilakukan dengan batu marmer ukuran 300×250x10 (mm) dengan parameter pemesinan untuk menghasilkan rekomendasi hasil grafir marmer terbaik. Proses iterasi nilai parameter pemesinan CNC router dilakukan sampai ada hasil grafir yang dapat digunakan untuk melakukan pemesinan produk kreatif sesungguhnya.

6. Evaluasi merupakan langkah untuk mendapatkan informasi tentang parameter pemesinan terbaik (putaran spindle, laju pemakanan, kedalaman pemotongan, jenis cutting tools) dikorelasikan dengan kualitas hasil grafir marmer dan keamanan terhadap peralatan dan mesin CNC router.

7. Pembuatan produk kreatif grafir batu marmer dari disain logo Polines, Logo Ristek Dikti, dan Logo Garuda menggunakan bahan ukuran 300x250x10 (mm).

8. Finishing pada grafir batu marmer/granit dilakukan dengan memberikan tampilan produk kreatif yang menawan.

9. Kegiatan ini meliputi merapikan sudut tajam, dan proses coating pada alur grafir dengan cat. Tahap akhir Kegiatan grafir batu marmer dibandingkan dengan cara konvensional mulai dari persiapan, pelaksanaan, sampai tahap finishing. Gambar 1 rancangan penelitian grafir batu marmer dengan mesin $\mathrm{CNC}$ router. (Gambar 1)

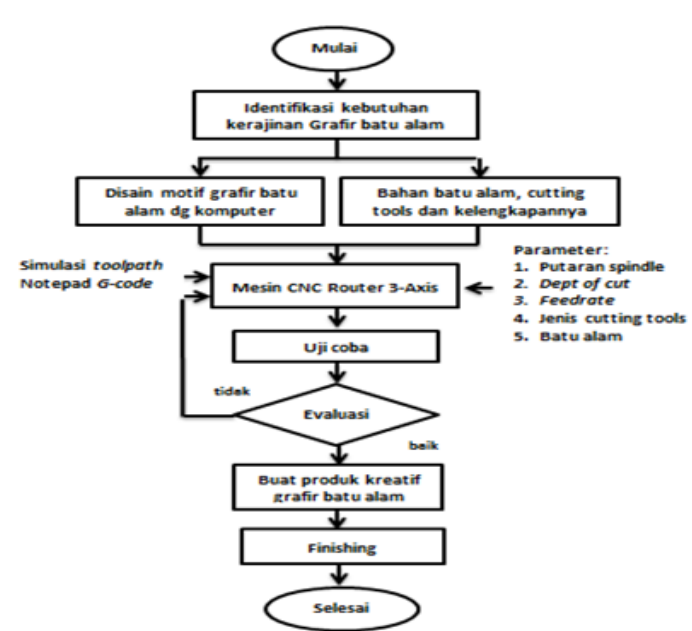

Sumber: Suharto,dkk. (2018)

\section{Gambar 1. Rancangan Penelitian}

\section{HASIL DAN PEMBAHASAN}

Data hasil eksperimen yang terkumpul tabel 1 kemudian dianalis untuk mangetahui pengaruh parameter pemesinan CNC milling terhadap karakteristik kualitas dan kondisi optimal dari kombinasi level parameter pemesinannya. Semakin tinggi kecepatan spindle, maka akan menghasilkan nilai kekasaran permukaan yang semakin kecil. Sebaliknya semakin rendah kecepatan spindle, maka akan menghasilkan nilai kekasaran permukaan yang semakin besar. Semakin tinggi kecepatan/laju pemakanan, maka akan menghasilkan nilai kekasaran permukaan yang semakin besar. Sebaliknya semakin rendah kecepatan/laju pemakanan, maka akan menghasilkan nilai kekasaran permukaan yang semakin kecil.

Eksperimen dilakukan dengan bahan baku batu marmer jenis Ornamental marble ukuran 300 x 250 x 10 (mm) menggunakan cutting tools jenis karbida, sistem pendingin air (collant) dan mesin $\mathrm{CNC}$ router.

Parameter pemesinan untuk putaran spindle 12000 (rpm), kecepatan/ laju pemakanan 2000 $(\mathrm{mm} / \mathrm{min})$, plunge $480(\mathrm{~mm} / \mathrm{min})$, pass depth 0.5 $(\mathrm{mm})$, step over $0.12(\mathrm{~mm})$ menghasilkan grafir batu marmer dengan kualitas baik memenuhi fungsional dan keamanan cutting tools mesin $\mathrm{CNC}$ router. 


\section{JURNAL SIMETRIK VOL 8, NO. 2, DESEMBER 2018}

Tabel 1. Hasil eksperimen grafir batu marmer

\begin{tabular}{|c|c|c|c|c|c|c|c|}
\hline \multirow[b]{2}{*}{ Eksperimen } & \multirow[b]{2}{*}{$\begin{array}{l}\text { Putara } \\
\text { spindle } \\
\text { (rpm) }\end{array}$} & \multirow[b]{2}{*}{$\begin{array}{c}\text { Laju } \\
\text { pemakanan } / \\
\text { feedrate } \\
(\mathrm{mm} / \mathrm{min})\end{array}$} & \multirow[b]{2}{*}{$\begin{array}{l}\text { Plunge } \\
\text { (mm } \mathrm{min})\end{array}$} & \multicolumn{3}{|c|}{ Kondisi } & \multirow[b]{2}{*}{$\begin{array}{c}\text { Nilai } \\
\text { kekasaran } \\
\text { permukaan } \\
(\mu \mathrm{m})\end{array}$} \\
\hline & & & & $\begin{array}{l}\text { Pass } \\
\text { depth } \\
(\mathrm{mm})\end{array}$ & $\begin{array}{l}\begin{array}{l}\text { Step } \\
\text { over } \\
(\mathrm{mm})\end{array} \\
\end{array}$ & $\begin{array}{c}\text { Kedalaman } \\
\text { pemakanan } \\
\text { (depth of cut) } \\
(\mathrm{mm})\end{array}$ & \\
\hline 1 & 8000 & 1000 & 480 & 0.5 & 0.12 & 7.2 & 16.15 \\
\hline 2 & 8000 & 1500 & 480 & 0.5 & 0.24 & 7.2 & 17.05 \\
\hline 3 & 8000 & 2000 & 480 & 0.5 & 0.36 & 7.2 & 18.25 \\
\hline 4 & 10000 & 1000 & 480 & 0.5 & 0.12 & 7.2 & 14.20 \\
\hline 5 & 10000 & 1500 & 480 & 0.5 & 0.24 & 7.2 & 14.55 \\
\hline 6 & 10000 & 2000 & 480 & 0.5 & 0.36 & 7.2 & 15.65 \\
\hline 7 & 12000 & 1000 & 480 & 0.5 & 0.12 & 7.2 & 10.55 \\
\hline 8 & 12000 & 1500 & 480 & 0.5 & 0.24 & 7.2 & 11.05 \\
\hline 9 & 12000 & 2000 & 480 & 0.5 & 0.36 & 7.2 & 11.35 \\
\hline
\end{tabular}

Sumber: Suharto,dkk. (2018)

Ujicoba yang lebih luas dilakukan untuk pembuatan produk kreatif bahan batu marmer dengan ukuran 300x250x10 (mm) dengan disain grafir logo Polines, logo Ristekdikti, dan logo Garuda. Gambar 2 proses pemesinan bahan batu marmer dengan mesin $\mathrm{CNC}$ router.

Eksperimen parameter pemesinan $\mathrm{CNC}$ router untuk grafir batu marmer menunjukkan pengaruh faktor laju/ kecepatan pemakanan (feedrate) paling tinggi terhadap nilai kekasaran permukaan artinya semakin tinggi feedrate makan permukaan semakin kasar. Selanjutnya kedalaman pemakanan ( $\mathrm{mm})$ juga berpengaruh terhadap kekasaran artinya semakin dalam pemakanan semakin kasar permukaannya.

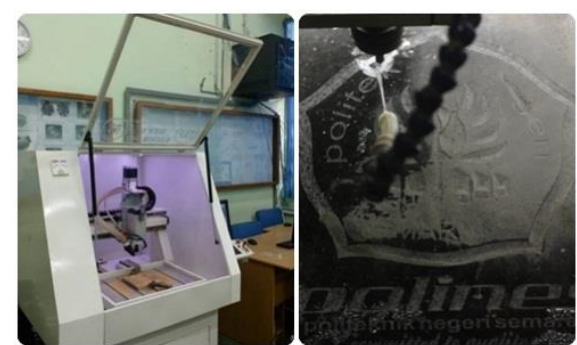

Sumber: Suharto,dkk. (2018)

Gambar 2. Proses Pemesinan CNC router

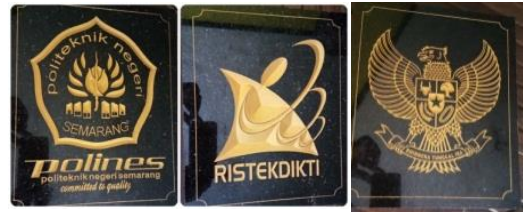

Sumber: Suharto,dkk. (2018)

Gambar 3. Produk Grafir setelah difinishing
Tabel 2. Parameter pemesinan terbaik $\mathrm{CNC}$ router

\begin{tabular}{cccccc}
\hline Produk & Cutting tools & $\begin{array}{c}\text { Putaran } \\
\text { spindle } \\
(\mathrm{rpm})\end{array}$ & $\begin{array}{c}\text { Feedrate } \\
(\mathrm{mm} / \mathrm{min})\end{array}$ & $\begin{array}{c}\text { Plunge } \\
(\mathrm{mm} / \mathrm{min})\end{array}$ & waktu \\
\hline $\begin{array}{c}\text { Logo } \\
\text { Polines }\end{array}$ & $\begin{array}{c}\text { Engraving bits } \\
\text { sudut 60 } \\
\text { Tip diameter } 0,5 \\
\text { mm }\end{array}$ & 12000 & 2000 & 480 & $01: 36: 22$ \\
$\begin{array}{c}\text { Logo } \\
\text { Engraving bits } \\
\text { sudut 60 }\end{array}$ \\
Ristekdikti & $\begin{array}{c}\text { Tip diameter } 0,5 \\
\text { mm } \\
\text { Engraving bits } \\
\text { sudut 30 }\end{array}$ & 12000 & 2000 & 480 & $01: 54: 53$ \\
Logo & 12000 & 2000 & 480 & $01: 40: 26$ \\
Garuda & $\begin{array}{c}\text { Tip diameter } 0,5 \\
\text { mm }\end{array}$ & & & & \\
\hline
\end{tabular}

Sumber : Suharto, dkk. (2018)

\section{PENUTUP}

\subsection{Kesimpulan}

Hasil penelitian yang telah dilakukan dapat ditarik kesimpulan:

1. Parameter pemesinan $\mathrm{CNC}$ router untuk grafir batu marmer kecepatan potong (cutting speed) 30 ( $\mathrm{m} / \mathrm{min})$, putaran spindle (spindle rotation) 12000 (rpm), kecepatan/laju pemakanan (feedrate) 2000 $(\mathrm{mm} / \mathrm{min})$.

2. Analisis faktor yang berpengaruh terhadap kekasaran permukaan grafir marmer pertama adalah kecepatan/laju pemakanan, kedalaman pemakanan artinya semakin tinggi nilainya semakin tinggi nilai kekasaran permukaan batu marmer.

3. Keamanan cutting tools terpilih cutting tools bahan karbida jenis Engraving bits sudut $60^{\circ}$ Tip diameter $0.5 \mathrm{~mm}$ mampu menyelesaikan grafir marmer logo polines waktu 01:36:22, logo ristekdikti 01:54:53, logo garuda 01:40:26 tanpa ganti cutting tool. Dengan pendingin cairan dromus yang kontinyu untuk menjaga cutting tools bekerja optimal.

4. Pengkayaan ragam produk kreatif grafir marmer dapat dimulai dengan disain input berbagai ragam foto pada halaman corelDraw menjadi siluet, dilanjutkan dengan setting Aspire vectric dan ekskusi mach3 pada mesin CNC router.

\subsection{Saran}

Penelitian pengembangan untuk produk kreatif yang dihasilkan dari mesin CNC Router 3 dimensi. Penelitian pengembangan untuk mesin $\mathrm{CNC}$ router dengan 4 sumbu, 5 sumbu. Penelitian pengembangan untuk material acrylic, aluminium, cetakan aneka produk kreatif untuk cindera mata.

\section{DAFTAR PUSTAKA}

Ardiansyah, 2011. Pengaruh Parameter Pemesinan pada Kayu terhadap Kekasaran Permukaan. Semarang:Skripsi. UNDIP.

Ardista, 2014. Generasi Millennial dalam Era Ekonomi Kreatif. Diakses melalui http://news.indonesiakreatif.net/gen-millennial/ 


\section{JURNAL SIMETRIK VOL 8, NO. 2, DESEMBER 2018}

Getting Started With 3D in Aspire. Introduction to Modelling Ocean Drive House Sign Tutorial . (c) Vectric Ltd The Coach House Upper Skilts Farm Gorcott Hill, Beoley B98 9ET UK. support@vectric.com.

www.vectric.com/support/trainingmaterial/aspire.html

Irfan Afandi. 2014. Belajar CorelDraw X4 Panduan Belajar dan Praktek. Modul CorelDraw. MAN 2

Banjarnegara https://www.scribd.com/doc/89167017/ModulCorel-Draw-X4.

Komsan Suriya, 2012. The Creative Economy: How people makes money from idea. The Empirical Econometrics and Quantitative Economic Letters Volume 1, Number 4, september2012.pp.180-182.

K.P., Patel, 2012. Experimental Analysis on Surface Roughness of CNC End Milling Process Using Taguchi Design Method. International Journal of Engineering Science and Technology (IJEST).Vol.4 No.2: 540-545

Nanda Afrilyan. 2015. Pemodelan Mesin CNC Engraving Untuk Pembuatan PCB. Fakultas Teknik Program Studi S-1 Teknik Mesin. Universitas Diponegoro. Skripsi.

Salam, A. Rohman. 2013, Proses Pembuatan Part RIB AT STN WFX 365.514 Komponen dari Sayap Pesawat Airbus A380, Laporan Kerja Praktek, Universitas Diponegoro, Semarang.

Suharto, Suryanto, Sarana. 2016. Pengembangan Rancang Bangun Canting Batik Cap Berkualitas Biaya Murah. Seminar Nasional Terapan Riset Inovatif (SENTRINOV) Semarang, 15 - 16 Oktober 2016, PROSIDING Vol. 01, Tahun 2016. ISSN: 2477 - 2097. pp.344-352

Suharto, Kunto Purbono, Ahmad Supriyadi, Karnowahadi. 2018. Rekayasa Mesin Milling CNC Untuk Kerajinan Batu Dalam Rangka Meningkatkan Daya Saing Industri Kreatif Di Pekalongan. Laporan penelitian Tahun ke-2 PSNi-DRPM Kemeristekdkti.

Suryanto, Suharto, VS Tri Priyo, Sarana, Iwan Hermawan, \& Agus Suwondo. 2014. Innovation of Making of the Batik Stamp Stand for Development of National Batik. Paper dalam Seminar International : Engineering International Conference- Education, Concept and Application of Green Technology, June 2014 at, UNNES, Semarang.

Suryanto, Suharto, VS Tri Priyo, Sarana, Iwan Hermawan, \& Agus Suwondo.2015. Pembuatan Canting Batik Cap (CBC) Menggunakan Mesin CNC Router Berbasis Software Mastercam. Science And Engineering National Seminar 1 (SENS 1) UPGRIS Semarang, 8 Agustus 2015. Prosiding ISBN : 978-602-0960-12-8. pp.95-100.

Surdia, T., Saito, S., 1985, Pengetahuan Bahan Teknik, Cetakan Ke-3, PT. Pradnya Paramita, Jakarta.
Takhesi Sato.G., Sugiarto.H.N., 2014. Menggambar Mesin menurut standar ISO, PT Pradnya Paramita, Jakarta. 